\title{
Assessment of trends in morbidity and mortality of the rural population of Rangat, Middle Andaman-A hospital based study
}

\author{
*Rehnuma Parvez ${ }^{1}$, P.Vijayachari ${ }^{1}$ \\ ${ }^{1}$ (Regional Medical Research Centre (ICMR), Post Bag No.13, Dollygunj,Port Blair,Andaman and Nicobar \\ Islands-744101, India.)
}

\begin{abstract}
The study was conducted as an attempt to gather information on the diseases prevalent in rural population of Rangat, Middle Andaman Islands. The study was carried out as a hospital based retrospective study by going through the three years viz., 2013, 2014 and 2015, hospital attendance records of the Community Health Centre Rangat and its five subcentres, Bakuntala, Nimbutala, Sabari, Dasarathpur and Kaushalya Nagar. The data of deaths for the years 2014 and 2015 was also collected from the death register. From the three years data, $28 \%$ of the cases were categorized as unclassified and constituted the largest proportion. Communicable and non-communicable diseases constituted almost equal proportions of cases (14\%). Hypertensive heart disease was found to be the most common non-communicable diseases present in (47\%) cases while among the infectious diseases, cases due to acute respiratory infection (ARI) were(45\%) followed by skin infections (20\%) and diarrhoeal diseases (14\%). Total no. of deaths analysed in 137 adult deaths, $64(43 \%)$ were due the non-communicable diseases, 35(24\%) due to senility and 12 (8\%) suicide. 25\% of the deaths due to non communicable diseases were attributed to Chronic kidney (renal) diseases (CKD). Suicidal deaths were also found to be higher among this population. The findings of the study suggest that Rangat has not remained untouched from epidemiologic transition where there is shift in trend of morbidity and mortality due to chronic non communicable diseases being more common than as due to infectious diseases. As per the findings of the present study, an in depth study is required to be find the prevalence of non communicable diseases, associated risk factors, socio behavioural determinants and mental health status in order to plan strategies for prevention and control of non communicable disease and better physical and mental health of this rural population.
\end{abstract}

Key words: India, Andaman Islands, rural, health, Rangat,

\section{Introduction}

India is a diverse country. Many of the states in India are going through a phase of epidemiological transition in health as one of the effects which is a shift in the disease spectrum from communicable to noncommunicable diseases (NCDs). ${ }^{1} \mathrm{NCDs}$, especially cardiovascular disease, diabetes mellitus, and stroke, have emerged as a major public-health problem in India. ${ }^{2}$ It is also recognized that the even among the poor and tribal population of India, the burden of non-communicable diseases exists ${ }^{3-7}$. Andaman and Nicobar islands $\left(92^{\circ}\right.$ to $94^{\circ}$ East and $6^{\circ}$ to $14^{\circ}$ North), a Union Territory of India is an archipelago of 555 islands/islets, stretching over $700 \mathrm{kms}$ from north to south, in the Bay of Bengal. The total population of the islands is $3,81,000$ (2011 census) including six aboriginal tribes and settlers from mainland India. ${ }^{8}$ The Andaman Island is divided into two major districts viz., North and Middle Andaman District and the South Andaman District. Middle Andaman Island is the central island of the Great Andaman archipelago of India, with a total area of $1,536 \mathrm{~km}^{2}$. Population of Middle Andaman consists of Bengali, Tamil and Keralite settlers. The island is also home to many of the indigenous Jarawa people. The main occupation of the inhabitants is farming and agriculture. Rangat, Billiground, Kadamtala, Bakultata and Betapur are the main towns of Middle Andaman. Rangat is also one of the three (tehsils) administrative divisions of the North and Middle Andaman District. Its population, according to the 2011 Census was 36,626 , mainly of Bengalis and Tamils. ${ }^{8}$ There is a scarcity of knowledge about the common health problems among the people of this remote area of the Middle Andaman Islands .Hence an attempt was made to study the health problems prevalent here. As it is well known that an accurate status of the health problems and disease profile among the adults and children can be drawn from community-based studies as compared to the hospital based studies. ${ }^{9,10}$ But community based surveys being expensive, we carried out a preliminary hospital based study to gather information on the diseases prevalent in this rural remote area of Andaman Islands. The objectives of the present study was to assess the proportions of patients attending hospitals by diseases and disease categories in Rangat, Middle Andaman, to assess the trends in the hospital attendance due to communicable and non-communicable diseases and also to assess the proportions of deaths by cause of death. 


\section{Methodology}

A retrospective study was carried out by collecting the data of the monthly hospital attendance for 3 years i.e., 2013 to 2015 from proforma II which contained the information of the monthly reports of OPD cases. This data included the number of outpatients treated at Community Health Centre (CHC) Rangat and five subcentres at Bakuntala, Nimbutala, Sabari, Dasarathpur and Kaushalya Nagar. The data of deaths for the years 2014 and 2015 was also collected from the death register. The data was entered in the excel sheets and this secondary data of hospital attendance and deaths were analyzed.

\section{Results \& Discussion}

The monthly reports from $\mathrm{CHC}$ and sub centres contain information about 71 diseases. The diagnosis was usually clinical. The cause of hospital attendance was categorized into ten categories viz, infections, non communicable diseases, deficiency disorders, degenerative/neurological disease, respiratory disease, gastrointestinal and liver diseases, pyrexia of unknown origin (PUO) , unclassified and others. From the three years data, $28 \%$ of the cases were categorized as unclassified and constituted the largest proportion. Communicable and non-communicable diseases constituted almost equal proportions of cases (14\%).Under the category of non-communicable diseases from 2013 to 2015, hypertensive heart disease was found to be the most common (47\%) followed by diabetes mellitus (42\%). Among the infectious diseases, acute respiratory infection (ARI) (45\%) was most common infection responsible for hospital attendance which was followed by skin infections (20\%) and diarrhoeal diseases (14\%).The number of cases of ARI was much higher in 2015 as compared to the previous two years. This upsurge may be due to viral respiratory infections which are more common in monsoon. The monthwise data of the number of hospital attendance in three years showed two peaks among cases due to ARI, first in January-February and the second in July. As the rainy season occurs twice a year in these islands, first under the influence of southwest monsoon it starts from mid May to September and then under northeast monsoon in November to January. Hence the two peaks of cases of ARI corresponds to the effects of two monsoons. ${ }^{11}$ Hospital attendance due to viral hepatitis and amoebiasis were much higher in 2013 as compared to the latter two years indicating that there was probably an upsurge in waterborne diseases that year (Fig. no.1).Among non communicable diseases ,hypertensive heart disease was the most common and which showed an upward trend during the three years studied. The second most common disease was diabetes mellitus.

Out of the 148 deaths analysed, $11(7 \%)$ deaths were in children aged less than 5 years. Among 137 adult deaths, $64(43 \%)$ of deaths were due the non-communicable diseases, 35(24\%) due to senility and $12(8 \%)$ suicide. Majority of the deaths were due the non-communicable diseases, and $25 \%$ of the deaths were attributed to Chronic kidney (renal) diseases (CKD) which was found to be the most common non-communicable diseases causing deaths. Only 4 deaths were due to infectious disease, 2 each of leptospirosis and tuberculosis.

\section{Figure}

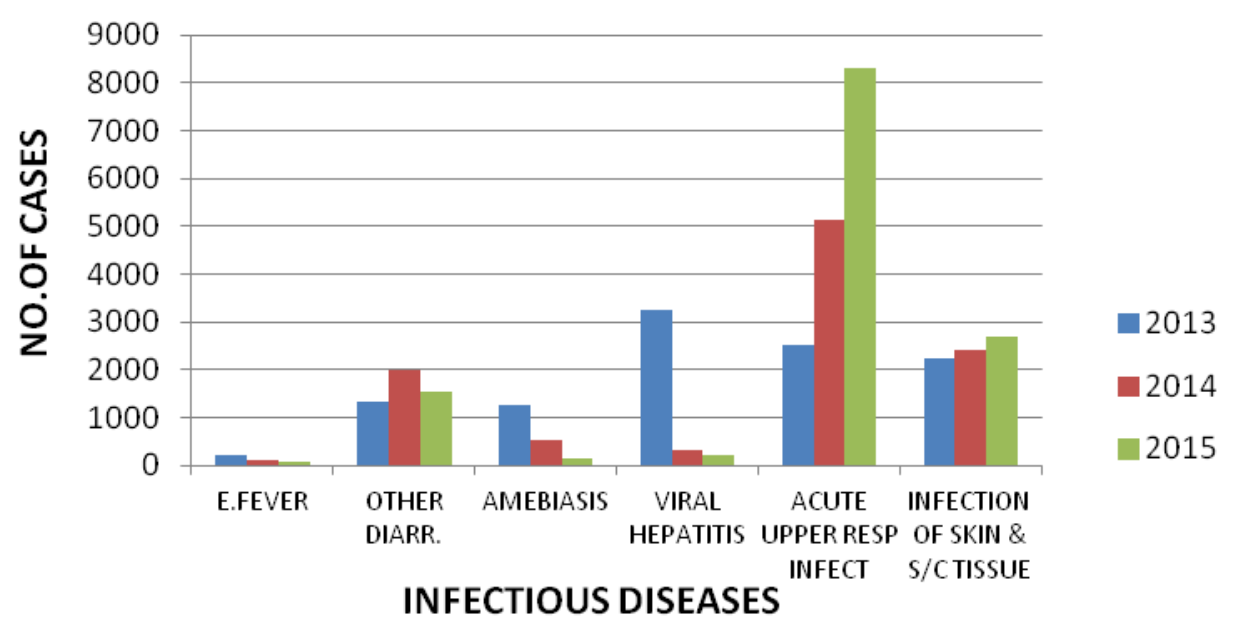

Fig no.1 Proportion of cases attributed to specific infectious diseases during 2013, 2014 and 2015. 


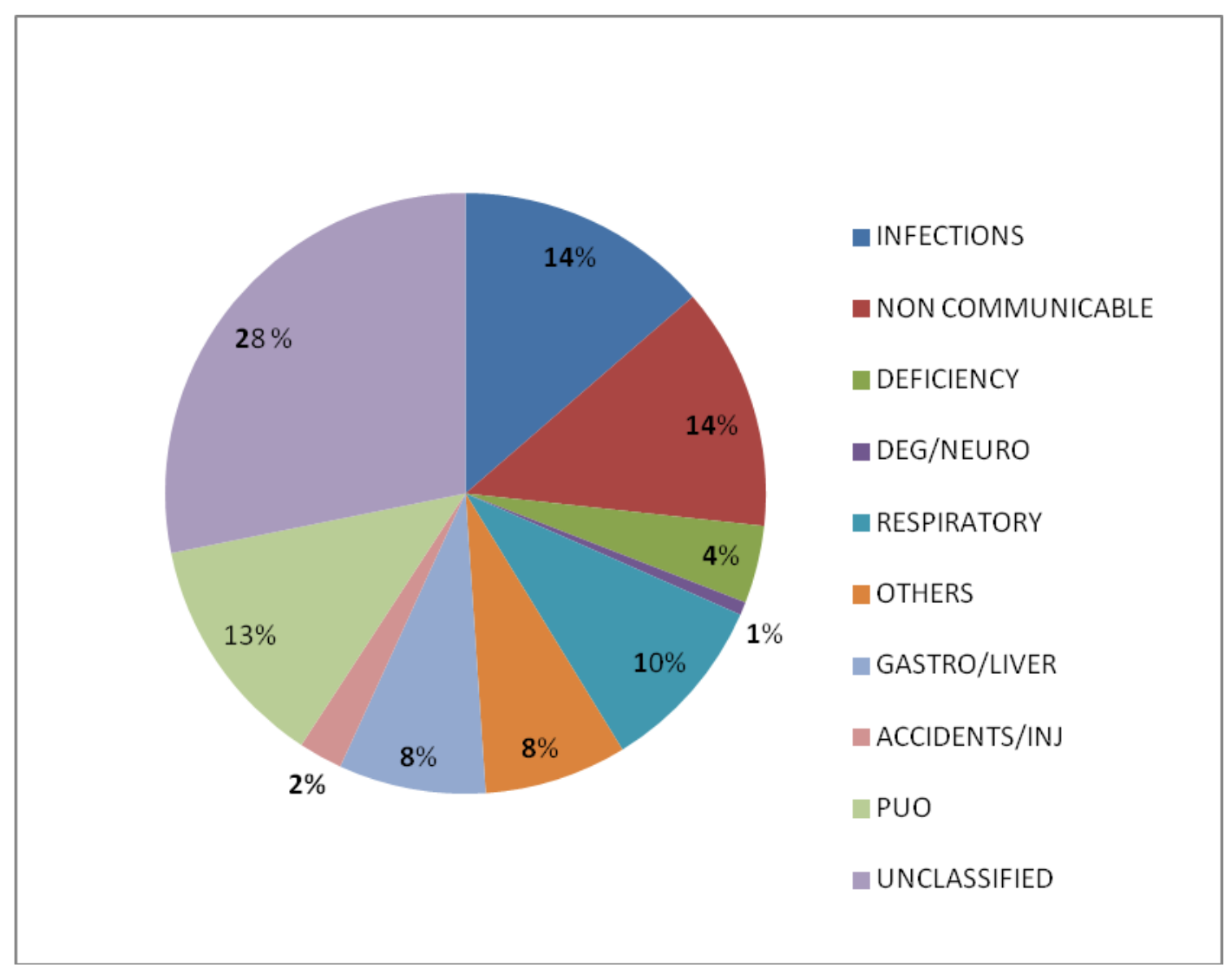

Fig no. 2 Causes of hospital attendance in Rangat, 2013, 2014 \& 2015

\section{Conclusion}

In the present study, acute respiratory infection (ARI) was the most common infections among the infectious diseases, followed by skin infections and diarrhoeal diseases. An upsurge of ARI observed in July 2015 was probably due to viral respiratory infections which are more common in monsoon here. Similarly an increase in cases viral hepatitis and amoebiasis observed in 2013 as compared to the latter two years indicating an upsurge in water-borne diseases that year. Hypertensive heart disease was the most common non communicable disease. Majority of the deaths were due the non-communicable diseases and Chronic Kidney Disease (CKD) was found to be the most common among them. Suicidal deaths were also found to be higher. The general shift from acute infectious and deficiency diseases characteristic of underdevelopment to chronic non communicable diseases characteristic of modernization and advanced levels of development is usually referred to as the "epidemiological transition". The most evident indicators of this transition are changes in the pattern of mortality, particularly in relation to the cause of death, as well as changes in morbidity. ${ }^{12}$ This transition is very much evident in the present study. Globally non-communicable diseases are the leading causes of death. According to global mortality data reported by the World Health Organization (WHO), chronic disorders such as coronary heart disease, stroke, cancer, chronic obstructive pulmonary disease, diabetes mellitus type 2,neurodegenerative disease and renal failure caused 38 million deaths in 2009 ,more than $62 \%$ of all deaths worldwide. ${ }^{13}$ Also the available data shows that nearly $80 \%$ of deaths due to non-communicable diseases occur in low and middle income countries. ${ }^{13}$ Rangat has not remained untouched with this epidemiologic transition. As per the findings of the present study, an in depth study is required to be find the prevalence of non communicable diseases like hypertension, diabetes mellitus and the associated risk factors and also understanding the dietary pattern, nutritional status and lifestyles of the people here. Moreover as evident from the analysis of the cause of death data, suicidal deaths are also common among this population hence a socio behavioural study will also help to find the issues related to suicidal deaths and mental health.

\section{Acknowledgements}

We thank the Chief Medical Officer, Medical officers and the other staffs of Community Health Centre Rangat for their cooperation and support during data collection. 


\section{Reference}

[1]. Mohan V, Deepa R. Risk factors for coronary artery disease in Indians. J Assoc Physicians India.2004; 52:95-7.

[2]. Reddy KS. Prevention and control of non-communicable diseases: status and strategies. New Delhi: Indian Council for Research on International Economic Relations; 2003. p. 30. p.

[3]. National Nutrition Monitoring Bureau, National Institute of Nutrition. Diet \& nutritional status of population and prevalence of hypertension among adults in rural areas. NNMB Technical Report No. 24. Hyderabad: National Institute of Nutrition; 2006.

[4]. Mukhopadhyay B, Mukhopadhyay S, Majumder PP. Blood Pressure profile of Lepchas of the Sikkim Himalayas: epidemiological study. Hum Biol 1996; 68: 131-45.

[5]. Kusuma YS, Babu BV, Naidu JM. Prevalence of hypertension 11. in some cross-cultural populations of Visakhapatnam district, South India. Ethn Dis 2004; $14: 250-9$.

[6]. Tiwari RR. Hypertension and epidemiological factors among 12. tribal labour population in Gujarat. Indian J Public Health 2008; 52: 144-6.

[7]. Kerketta AS, Bulliyya G, Babu BV, Mohapatra SS, Nayak RN. 13. Health status of the elderly population among four primitive tribes of Orissa India: a clinico-epidemiological study. Z Gerontol Geriatr 2009; 42 : 53-9.

[8]. Know Andaman, Directorate of Economics and Statistics, Andaman and Nicobar administration, Port Blair. Accessed Sept 2016. Available from http://www.and.nic.in.

[9]. Moisi JC, Nokes DJ, Gatakaa H, Williams TN, Bauni E, Levine OS, et al. Sensitivity of hospital-based surveillance for severe disease: a geographic information system analysis of access to care in Kilifi district, Kenya. Bull World Health Organ 2011; 89: $102-11$.

[10]. Arcury TA, Gesler WM, Preisser JS, Sherman J, Spencer J, Perin J. The effects of geography and spatial behavior on health care utilization among the residents of a rural region. Health Serv Res 2005; 40: 135-56.

[11]. Available from http://www.andamantourism.in/andamans-climate-india.html. Accessed Sept 2016.

[12]. McKeown, Robert E. "The Epidemiologic Transition: Changing Patterns of Mortality and Population Dynamics." American journal of lifestyle medicine 3.1 Suppl (2009): 19S-26S.

[13]. WHO.(2009a).World Health Statistics,2009.Geneva ,Switzerland. 